\title{
Micellar solubilization of ibuprofen - influence of surfactant head groups on the extent of solubilization
}

\author{
Carlota O. Rangel-Yagui, Helen Wei Ling Hsu, Adalberto Pessoa-Jr, Leoberto Costa Tavares* \\ Department of Biochemical and Pharmaceutical Technology, Faculty of Pharmaceutical Sciences, \\ University of São Paulo
}

*Correspondence:

L. C. Tavares

Department of Biochemical and

Pharmaceutical Technology, Faculty of

Pharmaceutical Sciences - USP

Av. Prof. Lineu Prestes, 580 - Bloco 16

05508-950 - São Paulo, SP

E-mail: leoberto@usp.br
An important property of micelles with particular significance in pharmacy is their ability to increase the solubility of poorly soluble drugs in water, thus increasing their bioavailability. In this work, the solubilization of ibuprofen (IBU) was studied in micellar solutions of three surfactants possessing the same hydrocarbon tail but different hydrophilic head groups, namely sodium dodecyl sulphate (SDS), dodecyltrimethylammonium bromide (DTAB), and $\mathrm{n}$-dodecyl octa(ethylene oxide) $\left(C_{12} E O_{8}\right)$. The results showed that, irrespective of the surfactant type, the solubility of IBU increased linearly with increasing surfactant concentration, as a consequence of the association between the drug and the micelles. The $80 \mathrm{mM}$ $D T A B$ and the $80 \mathrm{mM} \mathrm{C} \mathrm{EO}_{8}$ micellar solutions resulted in a 16fold increase in solubility of IBU when compared to the buffer solution, whereas the $80 \mathrm{mM}$ SDS micellar solution resulted in a 5.5-fold increase in IBU solubility. The highest value of molar solubilization capacity $(\chi)$ was obtained with DTAB, $\chi=0.97$, followed by $C_{12} E O_{8}, \chi=0.72$, and finally $S D S, \chi=0.23$. However, due to the stronger tendency of the nonionic surfactant in forming micelles in solution, at the same surfactant concentration, we obtained the same solubility of IBU in both DTAB and $C_{12} E O_{8}$.
Uniterms

- Micellar solubilization

- Surfactant

- Ibuprofen

\section{INTRODUCTION}

Surfactants are amphiphilic molecules, consisting of both hydrophilic and hydrophobic regions. These substances are known to play a vital role in many processes of interest in both fundamental and applied sciences. One important property of surfactants is the formation of colloidal-sized clusters in solutions, known as micelles, which have particular significance in Pharmacy because of their ability to increase the solubility of sparingly soluble substances in water (Mall et al., 1996). The ambivalence of amphiphiles towards an aqueous environment is responsible for the phenomenon of self-association of individual surfactant molecules resulting in a variety of micellar aggregate structures (Blankschtein et al., 1986). The concentration of a monomeric amphiphile (surfactant molecule) at which micelles appear is called the Critical Micelle Concentration (CMC). The occurrence of a CMC results from a delicate balance of intermolecular forces. The main attractive force results from the hydrophobic 
interaction among the nonpolar surfactant tails, whereas the main opposing repulsive force results from steric and electrostatic interactions (in the case of ionic and zwitterionic surfactants) between the surfactant polar head groups (Israelachvili, 1985; Rangel-Yagui et. al., 2004). Micelles are known to have an anisotropic water distribution within their structure. In other words, the water concentration decreases from the surface towards the core of the micelle, with a completely hydrophobic (waterexcluded) core. These aggregates exhibit an interfacial region separating the polar bulk aqueous phase from the hydrocarbon-like interior (Tanford, 1980; Israelachvili, 1985). As a consequence, micellar solutions consist of a special medium in which hydrophobic, amphiphilic or ionic compounds may be solubilized and reagents may be concentrated or separated in aqueous solution (Oliveira, Chaimovich, 1993). Moreover, the spatial position of a solubilized drug in a micelle will depend on its polarity: nonpolar molecules will be solubilized in the micellar core and substances with intermediate polarity will be distributed along the surfactant molecules in certain intermediate positions.

On the other hand, numerous drug delivery and drug targeting systems have been studied in an attempt to minimize drug degradation and loss, to prevent harmful side effects, and to increase drug bioavailability (Gref et al., 1994; Allen et al., 1995; Torchilin et al., 1995; Canto et al., 1999; Jones \& Leroux, 1999; Dalmora et al., 2001). Within this context, the utilization of micelles as drug carriers presents some advantages when compared to other alternatives such as soluble polymers and liposomes. Micellar systems can solubilize poorly soluble drugs and thus increase their bioavailability, stay in the body (blood) long enough to provide gradual accumulation in the required area, and their sizes permit them to accumulate in areas with leaky vasculature. Moreover, specific ligands can be attached to their outer surface in order to optimize the controlled release and specificity of pharmacological effect. Another advantage is that the micelles can be obtained in an easy and reproducible manner in large scale (Torchilin, 2001).

Therefore, the utilization of aqueous micellar solutions for drug solubilization can be advantageous for drug delivery purposes, with the possibility of increasing water solubility of poorly soluble drugs, improving bioavailability, reducing toxicity and other side effects, enhancing permeability across the physiological barriers, and substantial change in drug distribution (Torchilin, 2001).

Usually, the solubilization of a molecule by a surfactant can be evaluated based on two descriptors: molar solubilization capacity, $\chi$, and micelle-water partition coefficient, $K$ (Atwood, Florence, 1983). The $c$ value is defined as the number of moles of the solute (drug) that can be solubilized by one mol of micellar surfactant, and characterizes the ability of the surfactant to solubilize the drug. It can be calculated based on the general equation for micellar solubilization:

$$
\chi=\frac{\left(S_{t o t}-S_{W}\right)}{\left(C_{\text {surf }}-C M C\right)}
$$

where $S_{t o t}$ is the total drug solubility, $S_{W}$ is the water drug solubility, $C_{\text {surf }}$ is the molar concentration of surfactant in solution, and $C M C$ is the critical micelle concentration (Alvarez-Nuñes, Yalkowsky, 2000). Since above the $C M C$ the surfactant monomer concentration is approximately equal to the $C M C$, the term $\left(\mathrm{C}_{\text {surf }}-C M C\right)$ is approximately equal to the surfactant concentration in the micellar form and, therefore, $\chi$ is equal to the ratio of drug concentration in the micelles to the surfactant concentration in the micellar form.

On the other hand, the micelle-water partition coefficient is the ratio of drug concentration in the micelle to the drug concentration in water for a particular surfactant concentration, as follows:

$$
K=\frac{\left(S_{t o t}-S_{W}\right)}{S_{W}}
$$

Combining Equations (1) and (2), we can relate the two solubility descriptors. Accordingly, for a given surfactant concentration:

$$
K=\frac{\chi\left(C_{\text {surf }}-C M C\right)}{S_{W}}
$$

As can be seen, $K$ is related to the water solubility of the compound, in contrary to $\chi$ (Alvarez-Nuñes, Yalkowsky, 2000). In order to eliminate the dependence of $K$ on the surfactant concentration, a molar micelle-water partition coefficient, $K_{M}$, can be defined as follows:

$$
K_{M}=\frac{\chi(1-C M C)}{S_{W}}
$$

Ibuprofen (4-isobutil-2-phenyl-propionic acid) (IBU), $\mathrm{pKa}=4.8$ (Janjikhel, Adeyeye, 1999), is a well-known nonsteroidal anti-inflammatory drug widely used in inflammatory therapy (Figure 1). The main disadvantages of this family of drugs are the relatively short plasma halflife, and the significant gut- and nephrite-toxicities (Simó et al., 2002). Moreover, IBU is a poorly water-soluble drug 
(Janjikhel, Adeyeye, 1999). Therefore, the development of a drug delivery system allowing the controlled release of IBU would be useful, especially in high dose-dependent treatments, including chronic diseases such as rheumatoid arthritis.

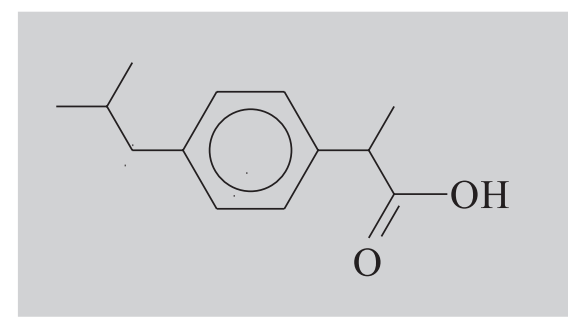

FIGURE 1 - Chemical structure of the anti-inflamatory drug ibuprofen.

Studies have been conducted on the transdermal delivery of IBU aiming the decrease of the side effects related to long-term treatments. Transdermal IBU delivery systems based on polymers, nonionic polyethylene oxide alkyl ether surfactants solutions, and liposomes have been investigated (Liso et al., 1995; Bula, Ghaly, 1995; Park et al., 2000; Suedee et al., 2002). The controlled release of IBU from injectable poloxamer-based gels applied to epidural analgesia was also studied by Paavola et al. (1998), and it was shown that the poloxamer gel prolongs the in vitro release of the drug relative to the corresponding control formulations.

In this work, the influence of the hydrophilic portion of surfactants (head group) on micellar solubilization of the drug ibuprofen (IBU) was investigated. Three different surfactants, a nonionic ( $n$-dodecyl octa(ethylene oxide)), a cationic ( $n$-dodecyltrimethylammonium bromide), and an anionic (sodium dodecyl sulphate), all presenting the same tail length, were studied. Although the ionic surfactants studied might be toxic and present restrictions for in vivo use, their investigation contributes significantly to the understanding of IBU solubilization.

\section{MATERIAL AND METHODS}

\section{Material}

Ibuprofen (IBU) and the cationic surfactant $n$ dodecyltrimethylammonium bromide (DTAB) were from Sigma (St. Louis, MO). The anionic surfactant sodium dodecyl sulphate (SDS) was from Pharmacia Biotech (Uppsala, Sweden). The nonionic surfactant $n$-dodecyl octa(ethylene oxide) $\left(\mathrm{C}_{12} \mathrm{EO}_{8}\right)$ was from Nikko Chemicals (Tokyo, Japan). The solutions were prepared in $5 \mathrm{mM}$ phosphate buffer $\mathrm{pH} 7.4$ (ionic strength $=0.011 \mathrm{M}$ ), utilizing water purified through a Millipore Milli-Q ionexchange system (Bedford, MA). All the other reagents were of analytical grade. The glassware used was washed in a 50:50 ethanol:1 $\mathrm{M}$ sodium hydroxide bath, followed by a $1 \mathrm{M}$ nitric acid bath, rinsed copiously with Milli-Q water, and finally dried in an oven.

\section{Determination of ibuprofen concentrations}

The concentration of IBU was determined spectrophotometricaly at $l=273 \mathrm{~nm}$ in a Beckman DU 640 (Fullerton, CA) spectrophotometer, utilizing a surfactant solution at the same molar concentration as blank. The extinction coefficient of the drug at this wavelenght was found to be $256.5 \mathrm{M}^{-1} \mathrm{~cm}^{-1}$ (Ridell et al.., 1999).

\section{Determination of critical micelle concentrations (CMC)}

The $C M C$ of the surfactants at $25{ }^{\circ} \mathrm{C}$ was determined in pure water, phosphate buffer $\mathrm{pH} 7.4$, as well as in phosphate buffer in the presence of IBU at saturation (4 $\mathrm{mM}$ ). The $C M C$ determinations for SDS and DTAB were based on the change in conductance with surfactant concentration, with the measurements performed in a MPC 227 Mettler-Toledo (Columbus, $\mathrm{OH}$ ) conductivimeter. The $C M C$ determinations for $\mathrm{C}_{12} \mathrm{EO}_{8}$ were based on the change in surface tension with surfactant concentration. A DuNoüy ring tensiometer (model 21, Fischer Scientific Tensiomat, Fair Lawn, NJ) was used to measure the surface tension. Each conductivity/surface tension measurement was repeated three times, and the typical error in the $C M C$ determination was less than $5 \%$.

\section{Solubility determination}

The solubility of IBU in SDS, DTAB, and $\mathrm{C}_{12} \mathrm{EO}_{8}$ solutions was measured at surfactant concentrations between 0 and $85 \mathrm{mM}$. Excess amounts of IBU were added to vials containing $2.0 \mathrm{~mL}$ of buffered surfactant solutions ( $\mathrm{SDS}, \mathrm{DTAB}$ or $\mathrm{C}_{12} \mathrm{EO}_{8}$ ). The sample vials were then rotated at $8 \mathrm{rpm}$ in an end-to-end rotator (Labquake, Barnstead/Thermolyne, Dubuque, IW) at $25^{\circ} \mathrm{C}$ for 24 hours. After this period, the samples were centrifuged at $8720 \mathrm{~g}$ for 20 minutes, $25^{\circ} \mathrm{C}$ (Centrifuge BR4, Jouan, Winchester, VA), and the concentration of solubilized IBU determined spectrophotometrically as described above. All the solubility experiments were carried out in triplicate. 


\section{Calculation of solubility descriptors}

The values of $\chi$ and $K_{M}$ were calculated from the solubility curves obtained for IBU and the three surfactants $\left(S_{\text {tot }}\right.$ vs. $\left.C_{\text {surf }}\right)$ and Equations (1) and (4).

\section{RESULTS AND DISCUSSION}

Figure 2 and 3 show the conductance $(\kappa)$ versus surfactant concentration plots obtained for SDS and $\mathrm{DTAB}$, respectively, at $25^{\circ} \mathrm{C}$. The $C M C$ is determined as
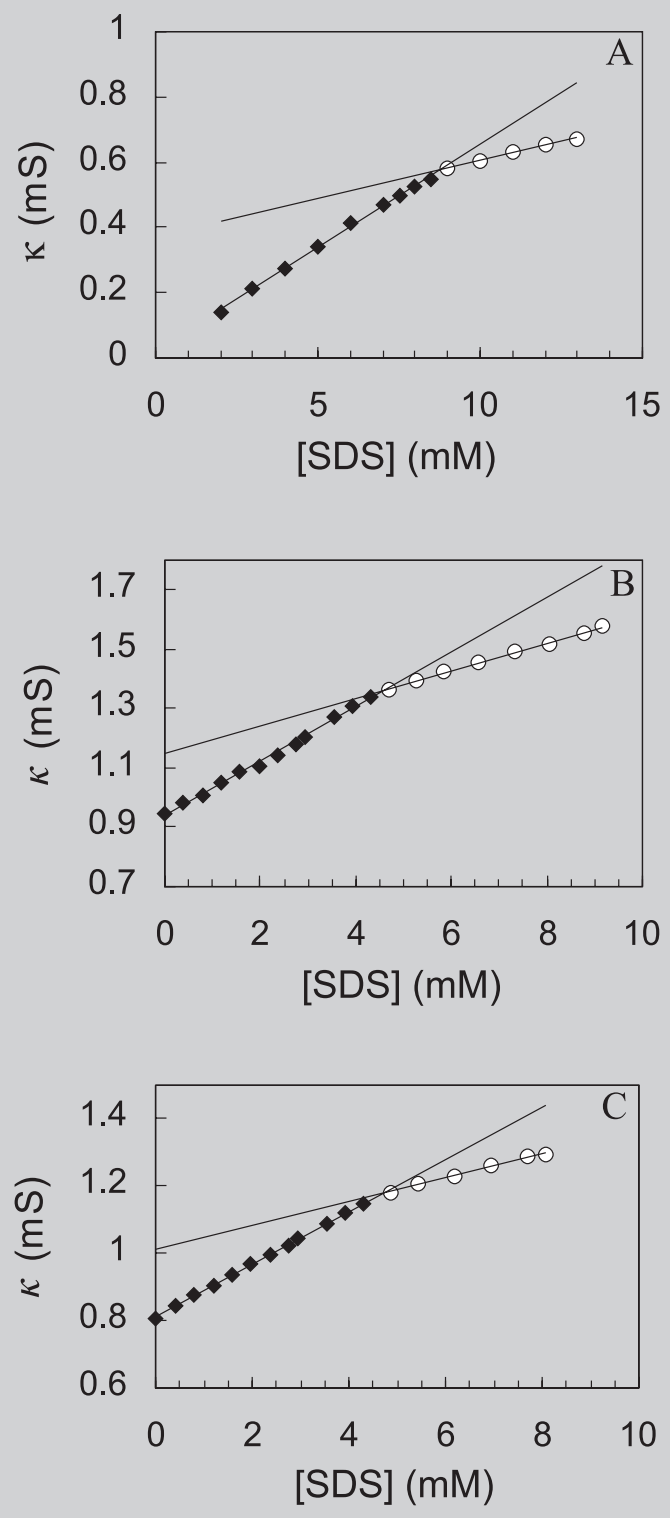

FIGURE 2 - Conductance $(\kappa)$ as a function of sodium dodecyl sulphate (SDS) concentration plots at $25^{\circ} \mathrm{C}$ in $\mathbf{A}$ pure water, B-phosphate buffer $\mathrm{pH}$ 7.4, and $\mathbf{C}$ - ibuprofensaturated $(4 \mathrm{~m} M)$ phosphate buffer $\mathrm{pH}$ 7.4. the intersection point between the two straight lines obtained. Figure 4 shows the surface tension $(\gamma)$ versus log surfactant concentration plots for $\mathrm{C}_{12} \mathrm{EO}_{8}$, at $25^{\circ} \mathrm{C}$. Again, the $C M C$ is obtained from the intersection point between the straight lines for low and high concentrations.

The results of $C M C$ for the three surfactants studied are summarized in Table I. The values obtained in water are in agreement with previous values reported in literature, according to which $C M C_{\mathrm{SDS}}=8.2 \mathrm{mM}$, $C M C_{\mathrm{DTAB}}=16.0 \mathrm{mM}$ (Rosen, 1989), and $C M C_{\mathrm{C} 12 \mathrm{EO} 8}=$ $88 \mu \mathrm{M}$ (Preté et al., 2002). As can be seen, the $C M C$ of
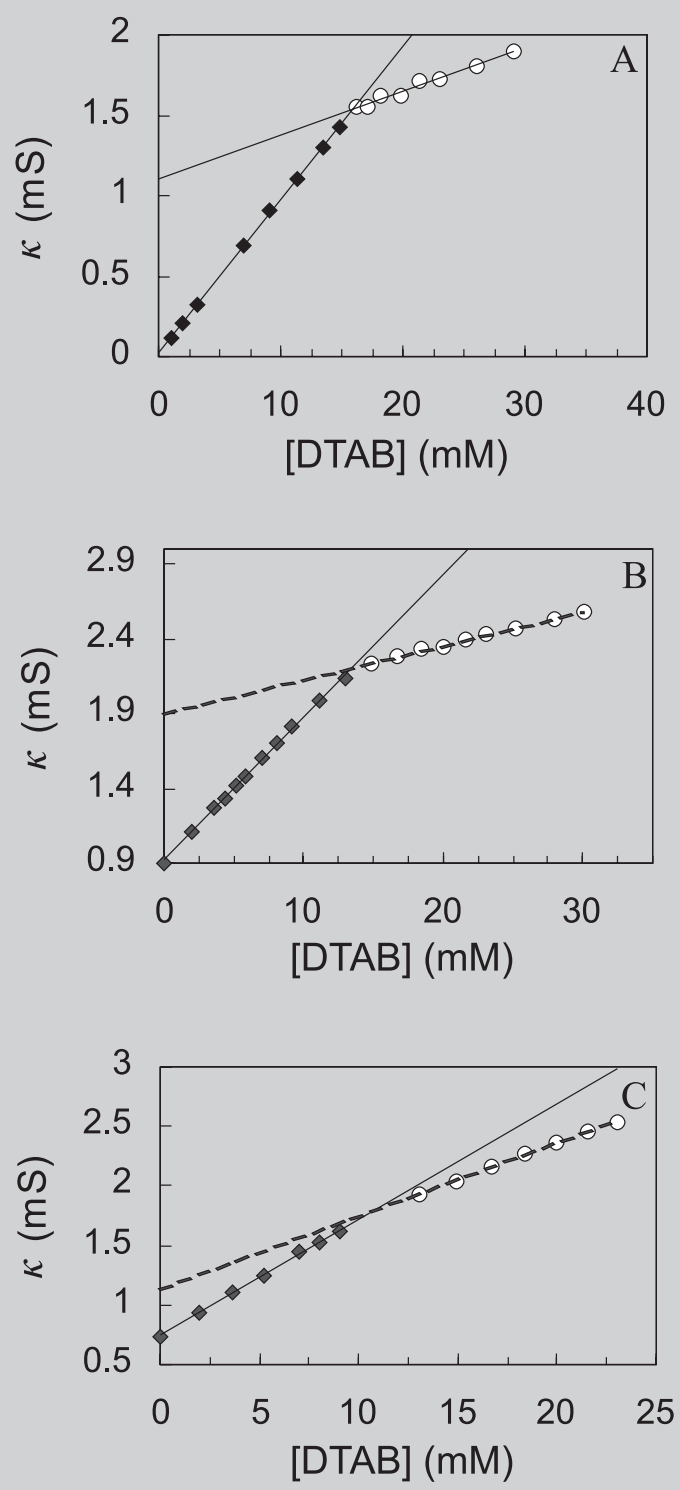

FIGURE 3 - Conductance $(\kappa)$ as a function of dodecyltrimethylammonium bromide (DTAB) concentration plots at $25^{\circ} \mathrm{C}$ in A-pure water, B-phosphate buffer $\mathrm{pH}$ 7.4, and $\mathbf{C}$-ibuprofen-saturated $(4 \mathrm{~m} M)$ phosphate buffer $\mathrm{pH}$ 7.4. 

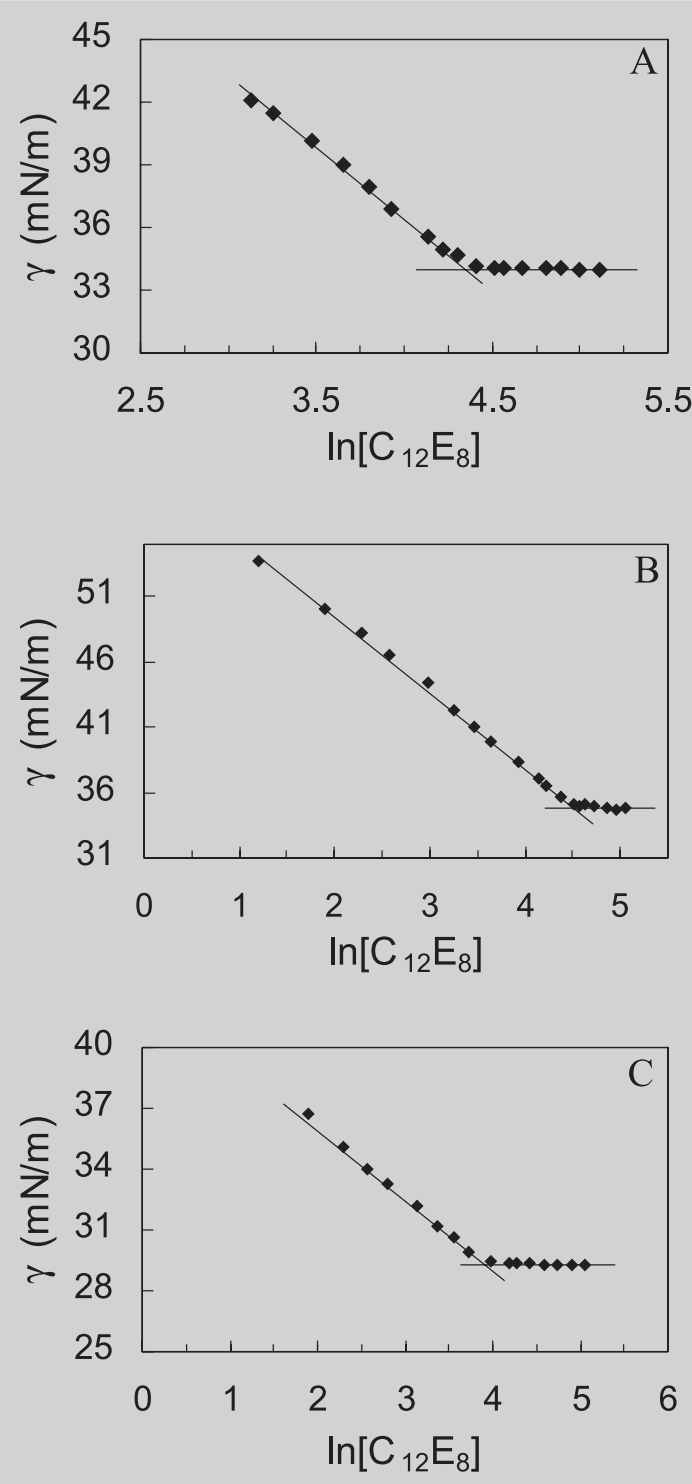

FIGURE 4 - Surface tension $(\gamma)$ as a function of $\log n$ dodecyl octa(ethylene oxide) $\left(\mathrm{C}_{12} \mathrm{EO}_{8}\right)$ concentration plots at $25^{\circ} \mathrm{C}$ in A-pure water, B-phosphate buffer $\mathrm{pH}$ 7.4, and C- ibuprofen-saturated (4 mM) phosphate buffer $\mathrm{pH}$ 7.4. ionic surfactants (SDS and DTAB) are considerably higher than the $C M C$ of the nonionic surfactant $\mathrm{C}_{12} \mathrm{EO}_{8}$, as a consequence of the electrostatic repulsions among the ionic surfactant head groups in the micelle. The low $C M C$ of nonionic surfactants, combined with the low toxicity, makes this class of surfactants particularly interesting for solubilization of drugs. The $C M C$ of SDS and DTAB were depressed in phosphate buffer. The depression of ionic surfactants $\mathrm{cmc}$ in the presence of electrolytes is due mainly to the decrease in the thickness of the electric double layer surrounding the ionic head groups and consequent decreased electrical repulsion between them in the micelle (Florence, Attwood, 2003). On the other hand, the $C M C$ of $\mathrm{C}_{12} \mathrm{EO}_{8}$ did not show significant change in phosphate buffer, as expected. This nonionic surfactant presents a polyethylene oxide (PEO) hydrophilic head group that interacts with water through hydrogen bonds. Therefore, the $C M C$ should not change in the presence of low concentration of electrolyte.

In the presence of IBU-saturated buffer, the $C M C$ of DTAB and $\mathrm{C}_{12} \mathrm{EO}_{8}$ were lowered, whereas no change was observed for the $C M C$ of SDS. In this respect, it has been described that molecules solubilized in the outer portion of the micelle core are most effective in reducing the $C M C$ than the ones solubilized in the inner core (Rosen, 1989). Therefore, if solubilization of IBU took place, the drug should be located in the inner core of SDS micelles, as a result of hydrophobic interactions with the surfactant tail.

In the case of $\mathrm{C}_{12} \mathrm{EO}_{8}$, IBU presents a terminal carboxyl group that may interact by hydrogen bonds with the PEO head groups. These interactions could drive the drug to the outer portion of the micellar core, in a way that the carboxyl group sticks to the palisade layer interacting with the PEO head groups, while the hydrophobic portion of the molecule stays preferentially in contact with the hydrophobic core (Rosen, 1989; Torchilin, 2001). Therefore, being located mainly in the outer portion of the micelle core, we could expect IBU to lower the $C M C$ of $\mathrm{C}_{12} \mathrm{EO}_{8}$.

TABLE I - Critical Micelle Concentrations $(C M C)$ experimentally determined for the surfactants SDS, DTAB and $\mathrm{C}_{12} \mathrm{EO}_{8}{ }^{*}$ in water, phosphate buffer $\mathrm{pH} 7.4$, and ibuprofen-saturated $(4 \mathrm{mM})$ phosphate buffer $\mathrm{pH} 7.4$

\begin{tabular}{lccc}
\hline Surfactant & $\mathbf{H}_{\mathbf{2}} \mathbf{O}$ & Critical Micelle Concentration $-\boldsymbol{C M C}$ & \\
& $8.7 \mathrm{mM}$ & Buffer & Buffer + IBU \\
\hline SDS & $15.9 \mathrm{mM}$ & $4.7 \mathrm{mM}$ & $4.7 \mathrm{mM}$ \\
DTAB & $81 \mu \mathrm{M}$ & $13.5 \mathrm{mM}$ & $11.0 \mathrm{mM}$ \\
$\mathbf{C}_{\mathbf{1 2}} \mathbf{E O}_{\mathbf{8}}$ & $85 \mu \mathrm{M}$ & $47 \mu \mathrm{M}$ \\
\hline
\end{tabular}

* SDS corresponds to sodium dodecyl sulphate, DTAB to dodecyltrimethylammonium bromide and $\mathrm{C}_{12} \mathrm{EO}_{8}$ to $n$-dodecyl octa(ethylene oxide). 
Finally, with DTAB, the electrostatic interactions between the negatively charged IBU and the positively charged DTAB must have caused a decrease in the repulsive forces between the head groups of the surfactant molecules, contributing to the micellization process and thus decreasing the $C M C$ value. Since IBU is an amphiphilic drug, we can view the DTAB/IBU system as a binary surfactant mixture. According to Puvvada and Blankschtein (1992), in aqueous solutions of binary surfactant mixtures synergistic interactions between the two surfactant species result in $C M C$ values that can be substantially lower than those in solutions containing the constituent single surfactants.

Figures 5, 6, and 7 present the results of IBU solubility as a function of the surfactants SDS, DTAB, and $\mathrm{C}_{12} \mathrm{EO}_{8}$ concentrations, respectively. Irrespective of the surfactant type, the solubility of IBU increased linearly with increasing surfactant concentration, as a consequence of the association between the drug and the micelles. As can be seen from the solubilization curves for IBU in SDS and DTAB, the increase in drug solubility is observed only for surfactant concentrations above the $C M C$ ( $4.7 \mathrm{mM}$ for SDS and $11 \mathrm{mM}$ for DTAB), clearly demonstrating that micellar solubilization is taking place. This relationship cannot be visualized from the solubilization curve of the drug in $\mathrm{C}_{12} \mathrm{EO}_{8}$ because of the very low $C M C$ of this nonionic surfactant $(47 \mu \mathrm{M})$. However, measurements at surfactant concentrations below the $C M C$ (data not presented) have shown no increase in IBU solubility, confirming the correlation between increasing solubility and micellization also for the nonionic surfactant. It is important to point out that the linear relations obtained for IBU refer only to

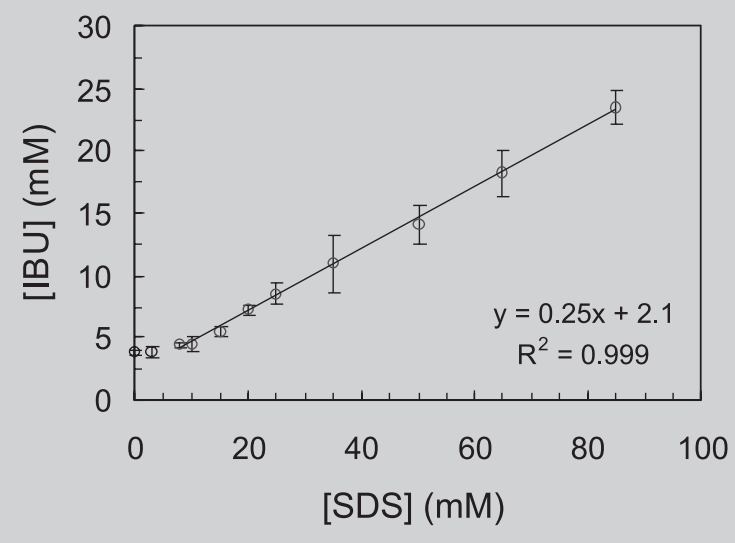

FIGURE 5 - Solubility curve of ibuprofen (IBU) as a function of sodium dodecyl sulphate (SDS) concentration in phosphate buffer $5 \mathrm{mM}$, pH 7.4 at $25^{\circ} \mathrm{C}$. The error bars represent $95 \%$ confidence limit for the measurements. surfactant concentrations above the CMC. The $80 \mathrm{mM}$ DTAB and the $80 \mathrm{mM} \mathrm{C}_{12} \mathrm{EO}_{8}$ micellar solutions resulted in a 16-fold increase in solubility of IBU when compared to the buffer solution, whereas the $80 \mathrm{~m} M$ SDS micellar solution resulted in a 5.5-fold increase in IBU solubility.

The influence of the anionic surfactant SDS on the solubilization of IBU was smaller than that of the other surfactants studied, as shown in Figure 5. IBU is an acid drug that is found to be $99.7 \%$ dissociated in $\mathrm{pH} 7.4$. As a consequence, the repulsion between the drug and the SDS head group may be expected to limit solubilization. Mall et al. (1996) observed similar effect for sulfanilamide and SDS, evidenced by a positive free energy of adhesion and positive enthalpy of transfer. According to these authors, the interaction between the head group of SDS and the drug has a dominant influence on solubilization. Nevertheless, it is important to take into account that the $\mathrm{pK}_{\mathrm{a}}$ of IBU must shift to a higher value in the presence of SDS micelles. Therefore, the ionized fraction of SDS is probably smaller than the predicted in pure water. One possibility of lowering the repulsion between SDS micelles and IBU would be switching the $\mathrm{pH}$ to lower values, in order to favor the molecular form of the drug.

One should keep in mind that the extent of solubilization of IBU in SDS micelles could increase when working at higher ionic strength values. In this case, there would be a screening of the charges in the SDS micelles and consequently lowering the electrostatic repulsion between the negatively-charged micelles and IBU. The screening of the charges would also lead to micellar growth, resulting in increased volume in the inner core of

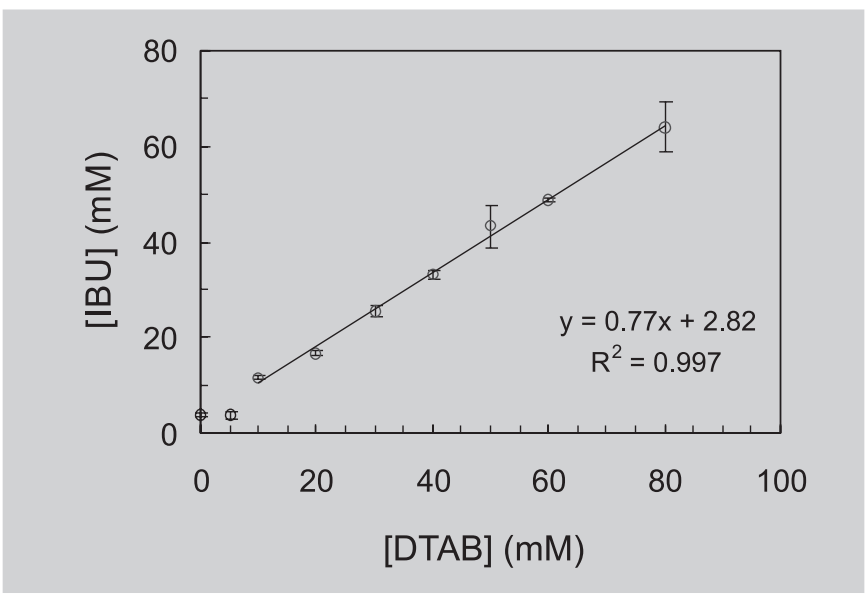

FIGURE 6 - Solubility curve of ibuprofen (IBU) as a function of dodecyltrimethylammonium bromide (DTAB) concentration in phosphate buffer $5 \mathrm{mM}, \mathrm{pH} 7.4$ at $25^{\circ} \mathrm{C}$. The error bars represent $95 \%$ confidence limit for the measurements. 
the micelle, where the IBU would be located. For DTAB micellar solutions, which are positively charged, the opposite effect would be observed.

On the other hand, the enhanced solubility of IBU in DTAB micellar solutions (Figure 6), is a consequence of the electrostatic interactions between the positively charged surfactant molecules and the negatively charged drug, resulting in mixed IBU/DTAB micelles and depressing the $C M C$, as discussed earlier. In fact, Caetano et al. (2002) had already observed this phenomenon of comicellization for the negatively charged surfactant SDS and trifluoperazine (TFP), an amphiphilic cationic drug used as antipsychotic and tranquilizer. The authors demonstrated based on SAXS (Small Angle X-ray Scattering) studies that the micellar ionization coefficient decreases upon TFP incorporation, until the intermicellar electrostatic interaction completely disappears over the scattering curves. Moreover, the electrostatic interaction between the positively charged drug and the negatively charged SDS must cause a decrease in the repulsive forces between the head groups of the surfactant. This effect lowered the $c m c$ and resulted in spherical-to-cylindrical micelle shape transformation. We believe that the same kind of behavior should take place for DTAB and IBU.

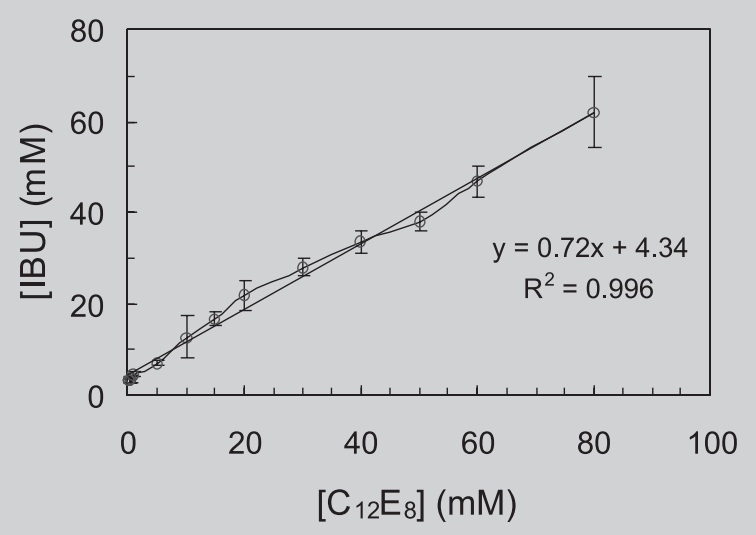

FIGURE 7 - Solubility curve of ibuprofen (IBU) as a function of $n$-dodecyl octa(ethylene oxide) $\left(\mathrm{C}_{12} \mathrm{EO}_{8}\right)$ concentration in phosphate buffer $5 \mathrm{mM}, \mathrm{pH} 7.4$ at $25^{\circ} \mathrm{C}$. The error bars represent $95 \%$ confidence limit for the measurements.

Similar solubility profiles were observed for IBU in DTAB and $\mathrm{C}_{12} \mathrm{EO}_{8}$ micellar solutions. Unlike ionic surfactants, with relative small polar head groups, micelles formed by PEO nonionic surfactants have an alternative locus for solubilization. Although there is space for hydrating water in the outer parts of these micelles, there is virtually none close to the hydrocarbon core due to the crowding of the polyoxyethylene chains (Barry, El Eini, 1976). As a result, a region that is largely purely polyoxyethylene rather than polyoxyethylene-water is formed, and may work as a site of solubilization of semipolar compounds, such as ionized IBU. In this particular case, hydrogen bonds might be taking place between IBU and the polyoxyethylene head groups.

The increased solubility of the drug in $\mathrm{C}_{12} \mathrm{EO}_{8}$ micellar solutions is not only a consequence of micelle-drug interaction, but also of the fraction of surfactant in the micellar form. For the nonionic surfactant $\mathrm{C}_{12} \mathrm{EO}_{8}$, at the same concentration of the ionic surfactants, the molar fraction of surfactant in the micellar form is higher, since the $C M C$ is much lower. In order to make this statement clear, the molar solubilization capacities of the surfactants, as well as the partition coefficients, were calculated and are presented in Table II. According to the values obtained, the molar solubilization capacity of DTAB, $\chi=0.97$, is higher than the molar solubilization capacity of $\mathrm{C}_{12} \mathrm{EO}_{8}, \chi$ $=0.72$, as a consequence of the electrostatic interactions. However, because of the stronger tendency of the nonionic surfactant in forming micelles in solution, at the same surfactant concentration, we obtained the same solubility of IBU both in DTAB and $\mathrm{C}_{12} \mathrm{EO}_{8}$. This can also be seen based on the molar micelle-water partition coefficients, $K_{M}^{D T A B}=243$ and $K_{M}^{C 12 E 8}=180$. Accordingly, the tendency of IBU to partition preferentially with the DTAB micelle is higher than the tendency to partition with the $\mathrm{C}_{12} \mathrm{EO}_{8}$ micelle.

The anionic surfactant SDS presented the lowest values of $\chi$ and $K_{M}$. As discussed earlier, IBU bears a negative charge and consequently repulsive interactions are present between the drug and the negatively charged head groups of SDS, reducing the possible loci of solubilization of this drug in SDS micelles.

Knowledge of the thermodynamic parameters controlling solubilization is helpful to a better understanding of the mechanisms involved in this process. From the thermodynamic point of view, the solubilization can be considered as a normal partitioning of the drug between two phases, micelle and aqueous, and the standard free energy of solubilization, $\Delta \mathrm{G}_{\mathrm{S}}{ }^{0}\left(\mathrm{~J} \mathrm{~mol}^{-1}\right)$, can be represented by the following expression (Torchilin, 2001):

$$
\Delta G_{S}^{o}=-R T \ln K_{M}
$$

where $R$ is the universal constant of the gases, $T$ is the absolute temperature, and $K_{M}$ is the molar partition coefficient between the micelle and the aqueous phase. The $\Delta \mathrm{G}_{\mathrm{S}}{ }^{0}$ value was calculated for all systems, and the results are presented in Table II. For all systems studied 
TABLE II - Solubilization parameters molar solubilization capacity $(\chi)$ and molar micelle-water partition coefficient $\left(K_{M}\right)$, and thermodynamic parameter free energy of solubilization $\left(\Delta \mathrm{G}_{\mathrm{S}}{ }^{\circ}\right)$ for the solubilization of ibuprofen in SDS, DTAB and $\mathrm{C}_{12} \mathrm{EO}_{8}$

\begin{tabular}{lccc}
\hline Micellar System & \multicolumn{3}{c}{ Solubilization and thermodynamic parameters } \\
& $\boldsymbol{\chi}$ & $\mathbf{K}_{\mathbf{M}}$ & $\mathbf{\Delta G}_{\mathbf{S}} \mathbf{~}^{\mathbf{0}}\left(\mathbf{k J ~ m o l}^{-\mathbf{1}}\right)$ \\
\hline SDS & 0.23 & 58 & -10.06 \\
DTAB & 0.97 & 243 & -13.61 \\
$\mathbf{C}_{\mathbf{1 2}} \mathbf{E O}_{\mathbf{8}}$ & 0.72 & 180 & -12.87 \\
\hline
\end{tabular}

SDS corresponds to sodium dodecyl sulphate, DTAB to dodecyltrimethylammonium bromide and $\mathrm{C}_{12} \mathrm{EO}_{8}$ to $n$-dodecyl octa(ethylene oxide). ${ }^{*}$ surfactant solutions, at $25^{\circ} \mathrm{C}$, in phosphate buffer $\mathrm{pH}$ 7.4. The error in the calculated parameters was $5 \%$.

$\Delta \mathrm{G}_{\mathrm{s}}{ }^{0}$ was negative, indicating spontaneous solubilization. The lowest value was observed for DTAB micellar system, confirming that the solubilization process of negatively charged drugs is energetically more favorable in cationic micellar systems, due to electrostatic interactions. On the contrary, the highest $\Delta \mathrm{G}_{\mathrm{S}}{ }^{0}$ value corresponded to the SDS micellar system.

\section{CONCLUSION}

In this work, the influence of the surfactant head group on the extent of ibuprofen solubilization was investigated. The anionic surfactant SDS presented the worst solubilization profile for IBU as a result of electrostatic repulsions between the drug and the surfactant head group, whereas the cationic surfactant DTAB provided the highest molar solubilization capacity of IBU due to the electrostatic attractions. Similar solubility profiles were observed for IBU in DTAB and $\mathrm{C}_{12} \mathrm{EO}_{8}$ micellar solutions. The increased solubility of the drug in $\mathrm{C}_{12} \mathrm{EO}_{8}$ micellar solutions was a consequence of IBU interaction with the PEO surfactant head group and also of the molar fraction of surfactant in the micellar form that is higher for nonionic surfactants due to the low $C M C$.

Therefore, nonionic surfactants could be considered the best alternative for solubilization of IBU, as well as of other acid drugs. This class of surfactants provides a reasonable molar solubilization capacity combined with low $C M C$ value, resulting in increased solubility of IBU. Moreover, the low toxicity of nonionic surfactants makes them particularly interesting for solubilization and drug delivery purposes. The possibility of combining nonionic surfactants with small amounts of cationic surfactants (considering the toxicity of this class of surfactants), resulting in mixed micellar systems, should also be investigated for solubilization of negatively charged drugs. In addition, Small Angle X-ray Scattering (SAXS) studies on the interaction of IBU with micelles of SDS, DTAB and
$\mathrm{C}_{12} \mathrm{EO}_{8}$ are in progress, aiming at a deeper understanding about the nature of these interactions as well as the properties of the aggregates obtained.

\section{RESUMO}

\section{Solubilização micelar do ibuprofeno - influência do grupo polar dos tensoativos no grau de solubilização}

Uma propriedade importante das micelas, do ponto de vista farmacêutico, refere-se ao potencial destas em solubilizar fármacos pouco solúveis em água, aumentando sua biodisponibilidade. No presente trabalho, estudou-se a solubilização de ibuprofeno (IBU) em soluções micelares constituídas de três tensoativos apresentando a mesma cauda apolar, porém diferentes grupos hidrofilicos. Os tensoativos estudados foram dodecil sulfato de sódio (SDS), brometo de dodeciltrimetilamônio (DTAB) e óxido de n-dodecil octaetileno $\left(C_{12} E O_{8}\right)$. De acordo com os resultados obtidos, a solubilidade do IBU aumentou linearmente com o aumento da concentração de todos os tensoativos estudados, devido às interações entre as micelas e o fármaco. O fármaco IBU apresentou um aumento de 16 vezes em sua solubilidade na presença de DTAB $80 \mathrm{mM}$ e de $\mathrm{C}_{12} E \mathrm{O}_{8} 80 \mathrm{mM}$. Por outro lado, na presença de SDS $80 \mathrm{mM}$ a solubilidade do IBU aumentou apenas 5,5 vezes. O maior valor para o parâmetro capacidade molar de solubilização $(\chi)$ foi observado com o tensoativo DTAB, $\chi=0,97$, seguido pelo $C_{12} E O_{8}, \chi=0,72$ e, finalmente, o SDS, $\chi=0,23$. Entretanto, devido à grande tendência do $C_{12} E O_{8} \mathrm{em}$ formar micelas, o perfil de solubilidade do IBU foi semelhante em DTAB e $C_{12} E O_{8}$.

Unitermos: Solubilização micelar. Cabeça polar. Ibuprofeno. Tensoativo. 


\section{ACKNOWLEDGEMENTS}

Carlota Rangel-Yagui is grateful for the PostDoctoral fellowship and financial support from FAPESP (Fundação de Amparo à Pesquisa no Estado de São Paulo). We acknowledge CAPES (Coordenação de Aperfeiçoamento de Pessoal de Nível Superior-Brazil) and CNPq (Conselho Nacional de Desenvolvimento Científico e Tecnológico - Brazil) for financial support. We also thank Prof. Iolanda M. Cuccovia for the use of her tensiometer. The authors are indebted to Prof. Daniel Blankschtein and his research group for very helpful discussions on micellar solubilization, critical comments and suggestions for improvement of this paper.

\section{REFERENCES}

ALLEN, T.M., HANSEN, C.B., MENENEZ, D.E.L. Pharmacokinetics of long-circulating liposomes. $A d v$. Drug. Deliv. Rev., v.16, p.267-284, 1995.

ALVAREZ-NÚÑEZ, F.A., YALKOWSKY, S.H. Relationship between polysorbate 80 solubilization descriptors and octanol-water partition coefficient of drugs. Int. J. Pharm., v.200, p.217-222, 2000.

ATWOOD, D., FLORENCE, A.T. Physicochemical principles of pharmacy. $3^{\text {rd }}$ ed. London: The MacMillan Press, 2003. 564 p.

ATWOOD, D., FLORENCE, A.T. Surfactant systems: Their chemistry, pharmacy and biology. New York: Chapman and Hall, 1983. 794 p.

BARRY, B.W., EL EINI, D.I.D. Solubilization of hydrocortisone, dexamethasone, testosterone and progesterone by long-chain polyoxyethylene surfactants. J. Pharm. Pharmac., v.28, p.210-218, 1976.

BLANKSCHTEIN, D., THURSTON, G.M., BENEDEK, G.B. Phenomenological theory of equilibrium thermodynamic properties and phase separation of micellar solutions, J. Chem. Phys., v. 85, n. 12, p.7268$7288,1986$.

BULA, D., GHALY, E.S. Liposome delivery systems containing ibuprofen. Drug. Dev. Ind. Pharm., v.21, n.14, p.1621-1629, 1995.
CAETANO, W., GELAMO, E.L., TABAK, M., ITRI R. Chlorpromazine and sodium dodecyl sulphate mixed micelles investigated by Small Angle X-Ray Scattering. $J$. Colloid Interf. Sci., v.248 p.149-157, 2002.

CANTO, G.S., DALMORA, S.L., OLIVEIRA, A.G. Piroxicam encapsulated in liposomes: characterization and in vivo evaluation of topical anti-inflammatory effect. Drug. Dev. Ind. Pharm., v.25, p.1235-1239, 1999.

DALMORA, M.E., DALMORA, S.L., OLIVEIRA, A.G. Inclusion complex of piroxicam with b-cyclodextrin and incorporation in cationic microemulsion. In vitro drug release and in vivo topical anti-inflammatory effect. Int. J. Pharm., v.222, p.45-55, 2001.

GREF, R., MINAMITAKE, Y., PERACCHIA, M.T., TRUBETSKOY, V.S., TORCHILIN, V.P., LANGER, R. Biodegradable long-circulating polymeric nanospheres. Science, v.263, p.1600-1603, 1994.

JANJIKHEL, R.K., ADEYEYE, C.M. Dissolution of ibuprofen enantiomers from coprecipitates and suspensions containing chiral excipients. Pharm. Dev. Technol., v.4, n.1 p.9-17, 1999.

JONES, M.C., LEROUX, J.C. Polymeric micelles - a new generation of colloidal drug carriers. Eur. J. Phar. Bio. Pharm., v.48, p.101-111, 1999.

LISO, P.A., REBUELTA, M., SANDROMAN, J., GALLARDO, A., VILLAR, A.M.. Antinociceptive and antipyretic properties of a new conjugated ibuprofenmethacrylic polymeric controlled delivery system. $J$. Control. Rel., v.33, n.3, p.429-436, 1995.

MALL, S., BUCKTON, G., RAWLINS, D.A. Dissolution behaviour of sulphonamides into sodium dodecyl sulphate micelles: A thermodynamic approach. J. Pharm. Sci., v.85, n.1, p.75-78, 1996.

OLIVEIRA, A.G., CHAIMOVICH, H. Effect of detergents and other amphiphiles on the stability of pharmaceutical drugs. J. Pharm. Pharmacol., v.45, p.850-861, 1993.

PAAVOLA, A., YLIRUUSI, J., ROSENBERG, P. Controlled release and dura mater permeability of lidocaine and ibuprofen from injectable poloxamer-based gels. J. Control. Rel., v.52, p.169-178, 1998. 
PARK, E.S., CHANG, S.Y., HAHN, M., CHI, S.C. Enhancing effect of polyethylene alkyl ethers on the skin permeation of ibuprofen. Int. J. Pharm., v.209, p.109-119, 2000 .

PRETÉ, P.S.C., GOMES, K., MALHEIROS, S.V.P., MEIRELES, N.C., DE PAULA, E. Solubilization of human erythrocyte membranes by non-ionic surfactants of the polyoxyethylene alkyl ethers series. Biophys. Chem., v.97, n.1, p.45-54, 2002.

PUVVADA, S.; BLANKSCHTEIN, D. Theoretical and experimental investigations of micellar properties of aqueous solutions containing binary mixtures of nonionic surfactants. J. Phys. Chem., v.96, p.5579-5592, 1992.

RANGEL-YAGUI, C.O., PESSOA JR, A., BLANKSCHTEIN, D. Two- phase aqueous micellar systems - an alternative method for protein purification (in press). Braz. J. Chem. Eng., v.21, n.4, 2004.

RIDELL, A., EVERTSSON, H., NILSSON, S., SUNDELOF, L.O. Amphiphilic association of ibuprofen and two nonionic cellulose derivatives in aqueous solution. J. Pharm. Sci., v.88, n.11, p.1175-1181, 1999.
ROSEN, M.J. Surfactants and interfacial phenomena, 2. ed. New York : John Wiley \& Sons, 1989. 448 p.

SIMÓ, C., GALLARDO, A., SAN ROMÁN, J., BARBAS, C., CIFUENTES, A. Fast and sensitive capillary electrophoresis method to quantitatively monitor ibuprofen enantiomers released from polymeric drug delivery systems. J. Chromatog. B, v.767, p.35-43, 2002.

SUEDEE, R., SRICHANA, T., RATTANANONT T. Enantioselective release of controlled delivery granules based on molecularly imprinted polymers. Drug Delivery, v.9, n.1, p.19-30, 2002

TORCHILIN, V.P., TRUBETSKOY, V.S. Which polymers can make nanoparticulate drug carriers long-circulating? Adv. Drug. Deliv. Rev., v.16, p.141-155, 1995.

TORCHILIN, V.P. Structure and design of polymeric surfactant-base drug delivery systems. J. Control. Rel., v.73, p.137-172, 2001.

Recebido para publicação em 05 de agosto de 2004. Aceito para publicação em 26 de novembro de 2004. 